\title{
Numerical investigation of natural convection of air in vertical divergent channels
}

\author{
O. Manca, S. Nardini, D. Ricci \& S. Tamburrino \\ Dipartimento di Ingegneria Aerospaziale e Meccanica, \\ Seconda Università degli studi di Napoli, Italy
}

\begin{abstract}
A numerical transient analysis of natural convection in air in vertical divergent channels is accomplished. The channel walls are heated at uniform heat flux, the problem is two-dimensional and laminar and the full Navier-Stokes and energy equations are employed. Results in terms of average wall temperature profile, as a function of the time, wall temperature distributions for inclination angle and minimum wall spacing are presented. The simulation allows the detection of complex structures of the flow inside and outside the channel. Temperature profiles as a function of time show overshoot and undershoot. A comparison between numerical flow patterns and experimental flow visualizations are also given and a good agreement is observed.
\end{abstract}

Keywords: natural convection, divergent channel, transient analysis.

\section{Introduction}

Natural convection in channels and parallel plates received very much attention for its application in engineering as reviewed in $[1,2]$. These configurations have been employed in chemical vapor deposition reactors, solar collectors, nuclear reactors, heat exchangers and thermal control of electronic systems $[3,4]$. Nowadays, trends in natural convection heat transfer are oriented toward either the seeking of new configurations to enhance the heat transfer parameters or the optimization of standard configurations $[5,6]$. In fact, recent research efforts have been devoted to define simple geometrical modification of the channel configurations to improve its thermal performance in natural convection [5-7]. Among them divergent vertical channels with two heated principal walls are very simple ones [9-12]. 
The divergent or convergent channels, even if symmetrically heated could have a significant view factor toward the surrounding which depends on the aperture angle. Then it is interesting to investigate the radiative effects on thermal performance of natural convection in air in divergent or convergent channels. About the divergent channel Agonafer and Watkins [8] studied numerically one-dimensional natural convection in a divergent channel for inclination angle values up to 8 degrees. An in-depth experimental study was carried out by Sparrow and Ruiz [9]. The principal walls were at uniform temperature and experiments were performed with water. Flow visualization indicated the presence of boundary layers adjacent to the channel walls with a recirculation loop occupying the remainder of the cross section. A single correlation between channel Nusselt and Rayleigh numbers for convergent, divergent and parallel walled channels was proposed.

Recently, Bianco et al. [10] carried out an experimental investigation on air natural convection in divergent channels with uniform heat flux at the principal walls. They found that the larger the Rayleigh number the worst the thermal performance of the channel, for several divergence angles larger than zero degrees and for low Rayleigh numbers. Flow visualization of air natural convection in a vertical divergent channel symmetrically heated at the walls, with a uniform heat flux, for different values of the divergence angle, the minimum channel spacing and the dissipated heat flux was carried in [11]. Results showed that the flow was laminar when the divergence angle was small $\left(\theta=2^{\circ}\right)$ and that the larger the divergence angle the larger the penetration depth of ambient air in the channel from its upper end section, which forms an air downflow in the central region of the channel and an air upflow parallel to the boundary layer.

A numerical simulation for vertical diverging and converging channels, with laminar steady state natural convection, was performed in [12]. The heated length of the walls was lower or equal to the wall length and it was isothermal. The adiabatic zone of the walls was placed either at the bottom end of the channel or at the top end.

Marcondes et al. [13] carried out a numerical investigation on natural convection in parallel, convergent and divergent channels using a fully elliptic procedure considering only the simple channel as computational domain. Both the channel walls were at uniform temperature and results were given for Prandtl number ranging from 0.7 to 88 . A correlation for average Nusselt number, Rayleigh number, in terms of maximum channel width and channel aspect ratio, and Prandtl number was proposed. They found that for convergent channels a recirculation region in the outlet zone was observed.

The analysis of wall temperature profiles presented in [11] and the observations provided in [12] suggests that a deeper insight into the fluid flow in natural convection in a vertical divergent channel should be given. Average wall temperature profiles depending on time, temperature distributions along the duct walls, and comparisons between flow visualization for experimental cases and stream function contours given for numerical simulations are presented in this paper for air natural convection in a vertical divergent channel symmetrically heated at the walls, for different divergence angles and channel spacing. 


\section{Mathematical description and governing equations}

The physical domain under investigation is shown in Fig. 1. It consists of two non-parallel plates that form a vertical divergent channel. Both plates are not thermally conductive and heated at uniform heat flux set equal to $120 \mathrm{~W} / \mathrm{m}^{2}$. The imbalance between the temperature of the ambient air, $\mathrm{T}_{0}$, and the temperature of the heated plates draws an air flow rate into the channel. The transient flow in the channel is assumed two-dimensional, laminar, incompressible, with negligible viscous dissipation. All thermophysical properties of the fluid are assumed constant, except for the dependence of density on the temperature (Boussinesq approximation) which gives rise to the buoyancy forces. The thermophysical properties of the fluid are evaluated at the ambient temperature, $T_{0}$, which is assumed to be $300 \mathrm{~K}$ in all cases. With the above assumptions, the governing equations in primitive variables are:

$$
\begin{aligned}
& \frac{\partial \mathrm{u}}{\partial \mathrm{x}}+\frac{\partial \mathrm{v}}{\partial \mathrm{y}}=0 \\
& \frac{\partial u}{\partial t}+u \frac{\partial u}{\partial x}+v \frac{\partial u}{\partial y}=-\frac{1}{\rho} \frac{\partial p}{\partial x}+v\left(\frac{\partial^{2} u}{\partial x^{2}}+\frac{\partial^{2} u}{\partial y^{2}}\right) \\
& \frac{\partial \mathrm{v}}{\partial t}+\mathrm{u} \frac{\partial \mathrm{v}}{\partial \mathrm{x}}+\mathrm{v} \frac{\partial \mathrm{v}}{\partial \mathrm{y}}=-\frac{1}{\rho} \frac{\partial \mathrm{p}}{\partial \mathrm{y}}+\mathrm{v}\left(\frac{\partial^{2} \mathrm{v}}{\partial \mathrm{x}^{2}}+\frac{\partial^{2} \mathrm{v}}{\partial \mathrm{y}^{2}}\right)-\mathrm{g} \beta\left(\mathrm{T}-\mathrm{T}_{\mathrm{o}}\right) \\
& \frac{\partial \mathrm{T}}{\partial \mathrm{t}}+\mathrm{u} \frac{\partial \mathrm{T}}{\partial \mathrm{x}}+\mathrm{v} \frac{\partial \mathrm{T}}{\partial \mathrm{y}}=\mathrm{a}\left(\frac{\partial^{2} \mathrm{~T}}{\partial \mathrm{x}^{2}}+\frac{\partial^{2} \mathrm{~T}}{\partial \mathrm{y}^{2}}\right)
\end{aligned}
$$
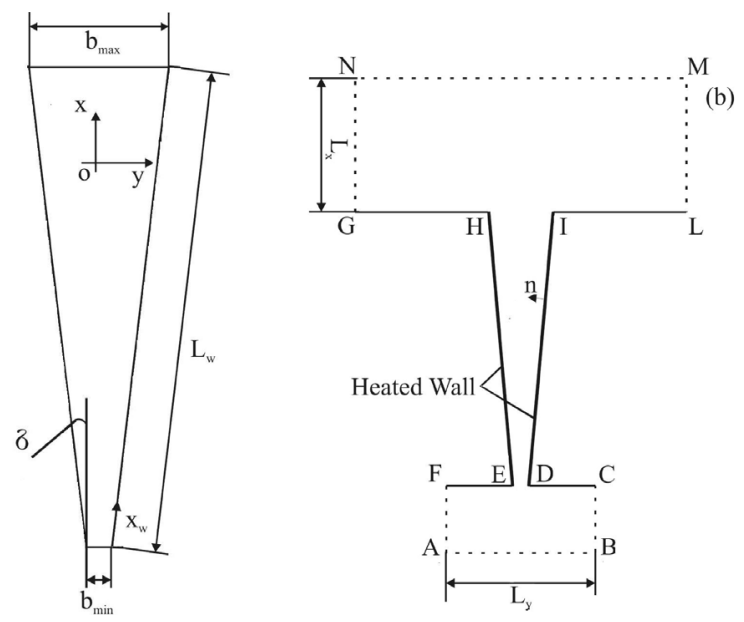

Figure 1: Geometrical configuration: (a) physical domain; (b) computational domain. 
The channel modified Rayleigh number and average Nusselt numbers are considered:

$$
\begin{aligned}
\mathrm{Ra}_{\mathrm{b}} & =\frac{\mathrm{g} \beta \mathrm{q}_{\mathrm{w}} \mathrm{b}^{5}}{\mathrm{v}^{2} \mathrm{~kL}} \mathrm{Pr} \\
\mathrm{Nu}_{\mathrm{b}} & =\frac{\mathrm{q}_{\mathrm{w}} \mathrm{b}}{\left(\mathrm{T}_{\mathrm{w}, \mathrm{av}}-\mathrm{T}_{\mathrm{o}}\right) \mathrm{k}}
\end{aligned}
$$

where $b$ is $b_{\min }$ or $b_{a v}$ or $b_{\max }$

$$
\mathrm{T}_{w, a v}=\frac{1}{\mathrm{~L}} \int_{0}^{\mathrm{L}} \mathrm{T}_{\mathrm{w}}(\mathrm{x}) \mathrm{dx}, \mathrm{q}_{\mathrm{w}}=\frac{1}{\mathrm{~L}} \int_{0}^{\mathrm{L}} \mathrm{q}_{\mathrm{W}}(\mathrm{x}) \mathrm{dx}
$$

\section{Numerical procedure}

Since the two plates are placed in an infinite medium, from a numerical point of view the problem is solved with reference to a computational domain of finite extent, as depicted in figure $1 \mathrm{~b}$, and by following the approach given in $[12,14]$. A finite extension computational domain is employed to simulate the free-stream condition and allows to account for the diffusive effects, peculiar in the elliptic model. The boundary conditions are given in Table 1 . The numerical model is solved using the commercial code FLUENT [15]. The segregated solution method is chosen to solve the governing equations, which are linearized implicitly with respect to the dependent variable equation. The second-order upwind scheme is chosen for the unsteady energy and momentum equations [15]. The SIMPLE scheme is chosen to couple pressure and velocity. Computation starts with zero values of velocities and with pressure and temperature values equal to the ambient ones, initial condition of the problem. The convergence criteria of $10^{-6}$ for the residuals of velocity components and of $10^{-8}$ for the residuals of the energy are assumed.

A grid dependence test is accomplished to realize the more convenient grid size by monitoring variables like average wall temperature, average Nusselt number and average outlet velocity for a divergent channel system with a spacing $\mathrm{b}=10$, divergent angle equal to $2^{\circ}$ and $\mathrm{Ra}_{\mathrm{bmin}}=3.3 \times 10^{3}$.

About the time step a value of $0.1 \mathrm{~s}$ is employed in the investigation after some tests on three different time steps $(0.05,0.1$ and $0.2 \mathrm{~s})$. Three mesh grids are analyzed, by doubling the number of nodes (from 27000 to 112000). It is observed that by doubling the number of the nodes in the channel, a variation of about $0.2 \%$ in terms of average wall temperature, $0.5 \%$ in terms of bulk temperature at the outlet section and $0.2 \%$ in terms of average velocity at the outlet section are observed. The mesh size with 56x560 nodes is employed in this investigation because it ensures a good compromise between the computational time and the accuracy requirements. The reservoir at the bottom have horizontal $\left(\mathrm{L}_{\mathrm{y}}\right)$ and vertical $\left(\mathrm{L}_{\mathrm{x}}\right)$ lengths set equal to twenty times the minimum spacing distance between the walls while the for the reservoir on the top $\mathrm{L}_{\mathrm{y}}$ and $\mathrm{L}_{\mathrm{x}}$ are, respectively, thirty-five and forty times than the minimum spacing. 
The validation of results is accomplished by comparing a numerical simulation with the experimental results. According to Bianco et al. $[10,11]$ the conductive and radiative heat losses are about $14 \%$ of the Ohmic wall heat flux. So a simulation for $\theta=2^{\circ}$ and $b_{\min }=10 \mathrm{~mm}$ has been carried out by applying a constant heat flux equal to $103 \mathrm{~W} / \mathrm{m}^{2}$ and a maximum difference of $2 \mathrm{~K}$ has been detected by comparing numerical results with experimental data.

Table 1: $\quad$ Boundary conditions for the fluid domain.

\begin{tabular}{|c|c|c|c||c|c|c|c|}
\hline Wall & $\mathbf{u}$ & $\mathbf{v}$ & $\mathbf{T}$ & Wall & $\mathbf{u}$ & $\mathbf{v}$ & $\mathbf{T}$ \\
\hline $\begin{array}{c}\mathrm{AF} \\
\text { and } \\
\mathrm{BC}\end{array}$ & $\frac{\partial \mathrm{u}}{\partial \mathrm{y}}=0$ & $\frac{\partial \mathrm{v}}{\partial \mathrm{y}}=0$ & $\mathrm{~T}=\mathrm{T}_{\mathrm{o}}$ & $\mathrm{EH}$ & $\mathrm{u}=0$ & $\mathrm{v}=0$ & $\mathrm{k}_{\mathrm{f}} \frac{\partial \mathrm{T}}{\partial \mathrm{n}}=-\mathrm{q}_{\mathrm{w}}$ \\
\hline $\mathrm{AB}$ & $\frac{\partial \mathrm{u}}{\partial \mathrm{x}}=0$ & $\frac{\partial \mathrm{v}}{\partial \mathrm{x}}=0$ & $\mathrm{~T}=\mathrm{T}_{\mathrm{o}}$ & $\mathrm{MN}$ & $\frac{\partial \mathrm{u}}{\partial \mathrm{x}}=0$ & $\frac{\partial \mathrm{v}}{\partial \mathrm{x}}=0$ & $\begin{cases}\frac{\partial \mathrm{T}}{\partial \mathrm{x}}=0 & \text { if } \mathrm{u}>0 \\
\mathrm{~T}=\mathrm{T}_{\mathrm{o}} & \text { if } \mathrm{u}<0\end{cases}$ \\
\hline $\begin{array}{c}\mathrm{EF}, \\
\mathrm{CD}, \\
\mathrm{IL},\end{array}$ & $\mathrm{u}=0$ & $\mathrm{v}=0$ & $\frac{\partial \mathrm{T}}{\partial \mathrm{x}}=0$ & $\mathrm{GN}$ & $\frac{\partial \mathrm{u}}{\partial \mathrm{y}}=0$ & $\frac{\partial \mathrm{v}}{\partial \mathrm{y}}=0$ & $\begin{cases}\frac{\partial \mathrm{T}}{\partial \mathrm{y}}=0 & \text { if } \mathrm{v}<0 \\
\mathrm{~T}=\mathrm{T}_{\mathrm{o}} & \text { if } \mathrm{v}>0\end{cases}$ \\
\hline $\mathrm{DI}$ & $\mathrm{u}=0$ & $\mathrm{v}=0$ & $\mathrm{k}_{\mathrm{f}} \frac{\partial \mathrm{T}}{\partial \mathrm{n}}=\mathrm{q}_{\mathrm{w}}$ & $\mathrm{LM}$ & $\frac{\partial \mathrm{u}}{\partial \mathrm{y}}=0$ & $\frac{\partial \mathrm{v}}{\partial \mathrm{y}}=0$ & $\begin{cases}\frac{\partial \mathrm{T}}{\partial \mathrm{y}}=0 & \text { if } \mathrm{v}>0 \\
\mathrm{~T}=\mathrm{T}_{\mathrm{o}} & \text { if } \mathrm{v}<0\end{cases}$ \\
\hline
\end{tabular}

\section{Results and discussions}

Average wall temperature profiles as a function of time, temperature profiles along the channel walls, and comparisons between flow patterns for experimental cases and stream function contours given for numerical simulations are presented for different divergence angles and channel spacing. This is useful in order to remark the thermal and fluid dynamic behaviours of natural convection in vertical divergent channel.

Fig. 2 reports the average wall temperature profiles for different angles and minimum wall spacings. It is observed, for $\theta=0^{\circ}$, a reduction of wall temperature by increasing the channel spacing up to $b_{\min }=20 \mathrm{~mm}$. For $b_{\min }=7.0$ $\mathrm{mm}$ (Fig. 2a) maximum average wall temperature is detected for $\theta=0^{\circ}$ while for $b_{\min }=10,20$ and $40 \mathrm{~mm}$ the simulations for $\theta=5^{\circ}$ reveal the maximum values at steady state. However, for $\theta=10^{\circ}$ and $15^{\circ}$ the steady state condition is not reached and oscillations are present, in accordance with [12]. The amplitude of the oscillations increase increasing the spacing between the walls. It is interesting that up to $b_{\min } \leq 10 \mathrm{~mm}$, the minimum average wall temperature are attained for $\theta=10^{\circ}$ and $15^{\circ}$ whereas for $b_{\min } \geq 20 \mathrm{~mm}$ the minimum value is obtained for $\theta=0^{\circ}$. For all divergence angles temperature overshoots are detected, the temperature profiles show that there is an initial increase of temperature up to the maximum value. The overshoots present different trends 
depending on the divergence angles. In fact, for $\theta=0^{\circ}, 2^{\circ}$ and $5^{\circ}$ the overshoot is attained at a lower instant at about $2 \mathrm{~s}$ whereas for $\theta=10^{\circ}$ and $15^{\circ}$ it is reached for time not less than $10 \mathrm{~s}$ and this time increases increasing the wall spacing $b_{\min }$.

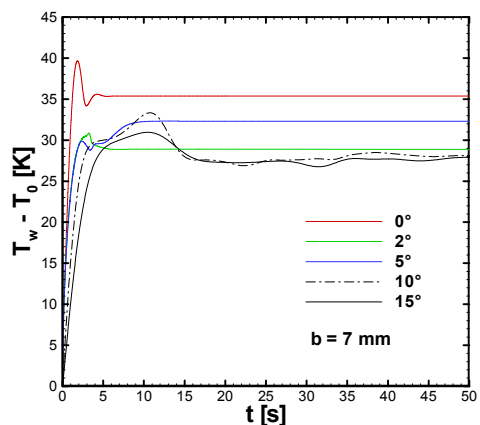

a)

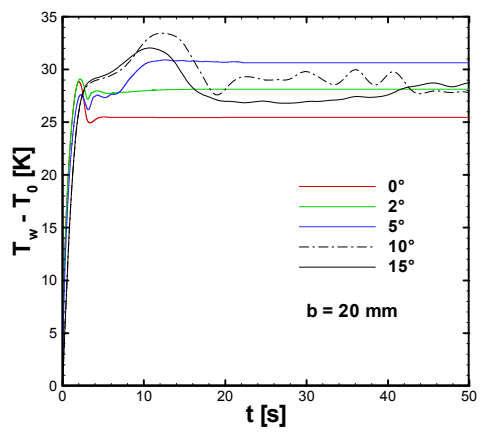

c)

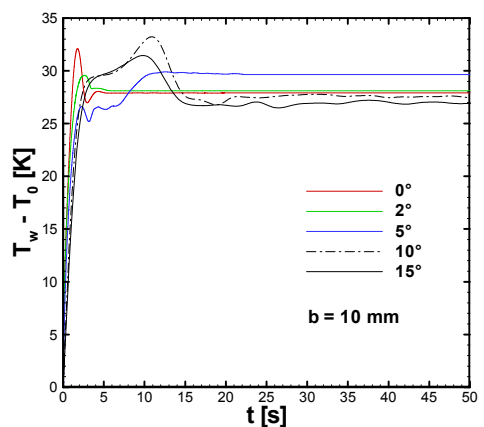

b)

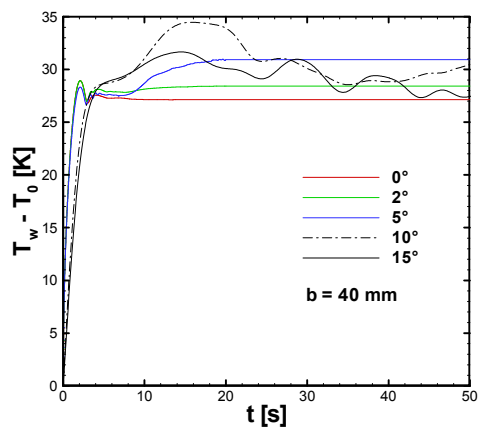

d)

Figure 2: Average wall temperature profiles depending on time: a) $b_{\min }=$ $7.0 \mathrm{~mm}$; b) $b_{\min }=10 \mathrm{~mm}$; c) $b_{\min }=20 \mathrm{~mm}$ and d) $b_{\min }=40 \mathrm{~mm}$.

Fig. 3 shows the wall temperature distributions at $t=50 \mathrm{~s}$. Maximum wall temperatures decrease for greater wall spacings. For $b_{\min }=7 \mathrm{~mm}$, in Fig. 3a, the highest wall temperature is noted for the parallel plate configuration, $\theta=0^{\circ}$. The difference between the maximum wall temperature for $\theta=0^{\circ}$ and $\theta=10^{\circ}$ is about $15^{\circ} \mathrm{C}$. The configuration with a divergence angle equal to $2^{\circ}$ presents the minimum value of maximum wall temperature, though the differences respect to the values for the other divergence angles are very small. For $b_{\min }=10 \mathrm{~mm}$, in Fig. $3 b$, the largest maximum wall temperature is again attained for $\theta=0^{\circ}$ but the difference respect to the values for the other configurations is significantly decreased, it is about $3{ }^{\circ} \mathrm{C}$. It is interesting to observe that for all considered $b_{\text {min }}$ values the lowest maximum wall temperature for $\theta=0^{\circ}$ is reached at 
$b_{\min }=40 \mathrm{~mm}$, in Fig. 3d. However, for the considered configurations it is convenient to give a slight divergence to the channel for lower $b_{\min } \leq 10 \mathrm{~mm}$.

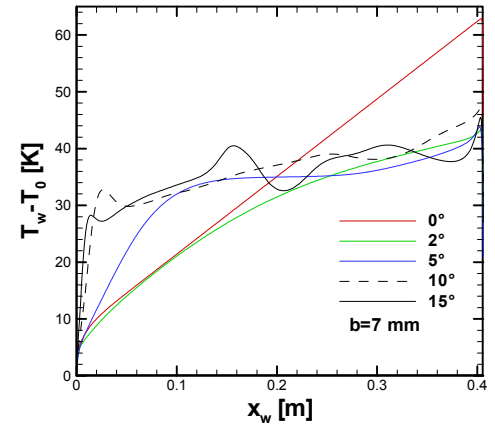

a)

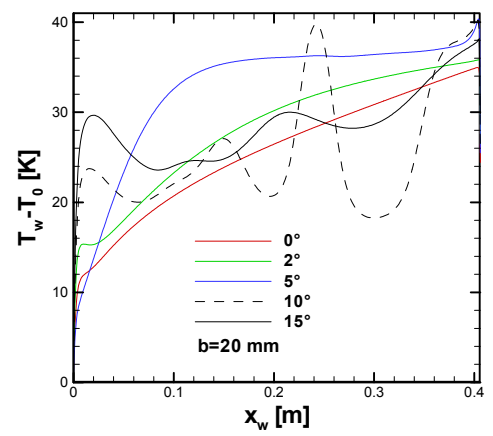

c)

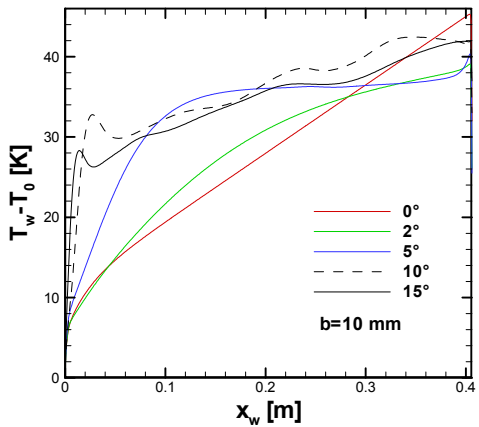

b)

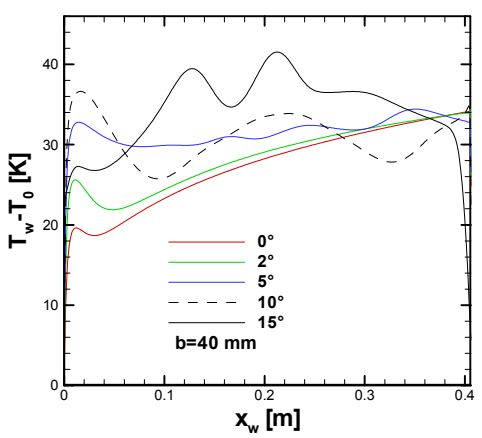

d)

Figure 3: Temperature distributions along the channel walls at $t=50 \mathrm{~s}$ : a) $b_{\min }=7 \mathrm{~mm}$; b) $b_{\min }=10 \mathrm{~mm}$; c) $b_{\min }=20 \mathrm{~mm}$ and d) $b_{\min }=40$ $\mathrm{mm}$.

Fig. 4 shows a comparison between flow patterns obtained for experimental cases and stream function contours of the numerical simulations for $\theta=2^{\circ}, 5^{\circ}$ and $10^{\circ}$ and $b_{\min }=20 \mathrm{~mm}$. In Fig. $4 a$ and $4 d$ one can remark the air laminar flow close to the wall, very similar to one into a parallel channel. Fig. $4 \mathrm{~b}$ and $4 \mathrm{e}$ show that increasing the divergence angle the air layer adjacent to the wall in the lower half height of the channel thickens. At mid-height the air layer becomes thinner because of the parallel upflow of the air towards the channel exit, which occurs together with an ambient air downflow from the exit section. Considering $\theta=$ $10^{\circ}$ a deeper penetration of the ambient air and an upflow closer to the boundary layer which improve heat transfer rate are revealed. At x values larger than about $100 \mathrm{~mm}$ the flow is very wavy because of the interaction between the air close to the wall and the vertical air downflow in the central region of the channel. 


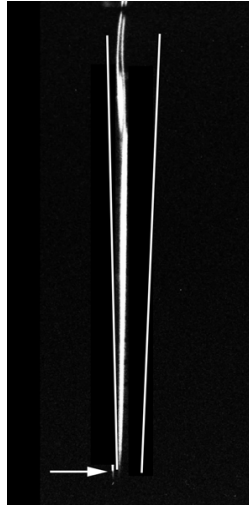

a)

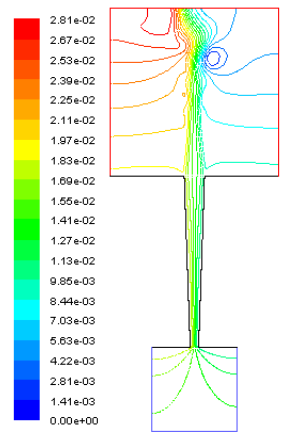

d)

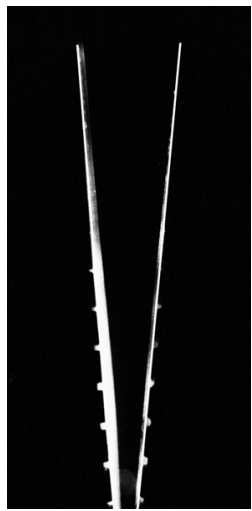

b)

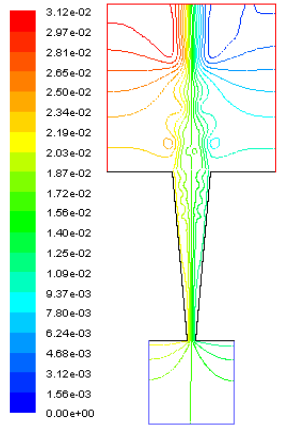

e)

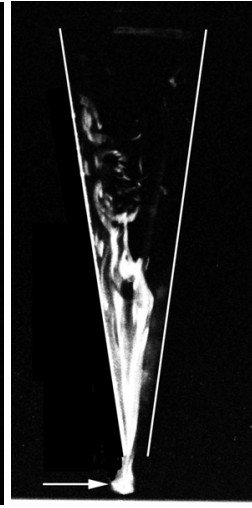

c)

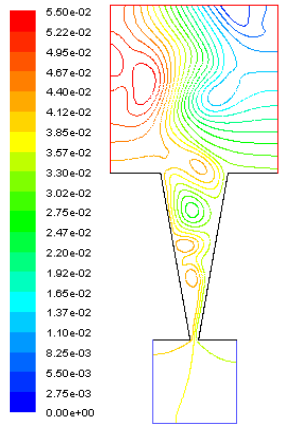

f)

Figure 4: $\quad$ Flow patterns $(a, b, c)$ of experimental cases and stream function contours $(\mathrm{d}, \mathrm{e}, \mathrm{f})$ of numerical simulations for $\mathrm{b}_{\min }=20$ and $\theta=2^{\circ}, 5^{\circ}$ and $10^{\circ}$ at $\mathrm{t}=50 \mathrm{~s}$.

\section{Conclusions}

Transient natural convection in a divergent vertical channel, with the wall heated symmetrically at uniform heat flux, was numerically investigated. A two dimensional transient laminar regime was considered and solved by a finite volume method employing the commercial code Fluent. Results showed that the average wall temperature as a function of time, for divergence angles greater than $5^{\circ}$ presented oscillations which increased their amplitude at increasing the wall spacing. In all configurations overshoot and undershoot were detected. Temperature profiles along the walls showed that for angles greater than $5^{\circ}$ periodic trends due to the cold inflow in the divergent channel were detected. In fact, the flow visualization and the stream function fields confirmed the disturbances inside the channel for higher divergence angles, $\geq 10^{\circ}$. For lower channel spacing, $7 \mathrm{~mm}$, a small divergence angle allows to reduce significantly the maximum wall temperature whereas for higher wall spacings the divergence 
of the channel do not provide a decrease in terms of maximum wall temperature. The comparison between experimental flow visualizations and stream function fields obtained numerically were in very good agreement. Moreover, the complex flow structures detected in the channel allow the configuration with a divergence angle equal to $5^{\circ}$ as a critical configuration to be defined.

\section{Nomenclature}

b channel spacing, $\mathrm{m}$

$\mathrm{g}$ acceleration of gravity, $\mathrm{m} \mathrm{s}^{-2}$

Gr channel Grashof number

$\mathrm{k}$ thermal conductivity, $\mathrm{Wm}^{-1} \mathrm{~K}^{-1}$

L channel length, $m$

$\mathrm{Nu} \quad$ Nusselt number

Pr Prandtl number

q heat flux, $\mathrm{W} \mathrm{m}{ }^{-2}$

$\mathrm{Ra}$ channel Rayleigh number

$\mathrm{T}$ temperature, $\mathrm{K}$

$\mathrm{x}, \mathrm{y}$ coordinates along the plate, $\mathrm{m}$

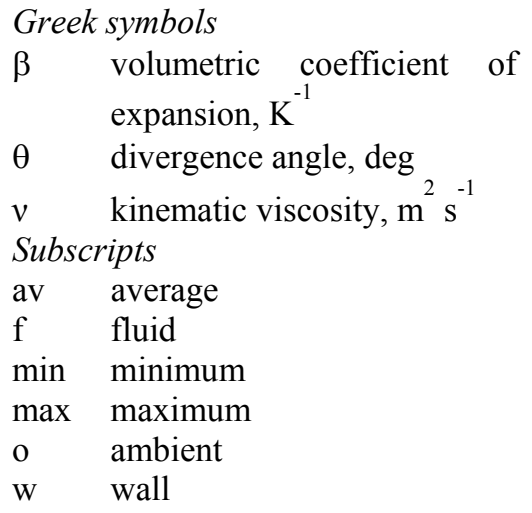

\section{Acknowledgement}

This work was supported by SUN with a 2007 grant.

\section{References}

[1] Manca, O., Morrone, B., Nardini, S., \& Naso, V., Natural Convection in Open Channels in Computational Analysis of Convection Heat Transfer, Sundén B. and Comini G. Editors, WIT Press, Southampton, Chap. 7, pp. 235-278, 2000.

[2] Bianco, N., Morrone, B., Nardini, S., \& Naso, V., Air natural convection between inclined parallel plates with uniform heat flux at the walls, International Journal of Heat and Technology, 18, pp. 23-46, 2000.

[3] Gebhart, B., Jaluria, Y., Mahajan, R. \& Sammakia, B., Buoyancy-Induced Flows and Transport, Hemisphere Publ. Corp., Washington, D.C, 1998.

[4] Raithby, G. D. \& Hollands, K. G. T., Natural Convection, in Handbook of Heat Transfer, Rohsenow, W. M., Hartnett, J. P., Cho, Y. I. editors, McGraw-Hill, New York, Chap. 7, pp. 4.1-4.99, 1998.

[5] Bejan, A., Shape and Structure, from Engineering to Nature, Cambridge University Press, Cambridge, 2000. 
[6] Ledezma, G. A., \& Bejan, A., Optimal geometric arrangement of staggered vertical plates in natural convection, ASME Journal of Heat Transfer, 119, pp. 700-708, 1997.

[7] Kim, S. J., \& Lee, S. W., Air Cooling Technology for Electronic Equipment, CRC Press, Boca Raton, FL, 1998.

[8] Agonafer, D., \& Watkins, C. B., Numerical solution of natural convection between diverging plates, ASME Paper 84-WA, HT 32, 1983.

[9] Sparrow, E. M., \& Ruiz, R., Experiments on natural convection in divergent vertical channels and correlation of divergent, convergent, and parallel-channel nusselt numbers, International Journal of Heat and Mass Transfer, 31, pp. 2197-2205, 1988.

[10] Bianco, N., Manca, O., Nardini, S. \& Naso, V., Air natural convection in a divergent channel with uniformly heated plates, Proceedings, XIX Congresso Nazionale sulla Trasmissione del Calore UIT, pp. 89-94, 2001.

[11] Bianco, N., Manca, O., Nardini, S. \& Naso, V., Visualization of natural convection in a vertical divergent channel plates, Proceedings, Eurotherm Seminar 71 on Visualization, imaging and data analysis in convective heat and mass transfer, pp. 117-122, Reims, October 28-30, 2002.

[12] Bejan, A., da Silva, A. K., \& Lorente, S., Maximal heat transfer density in vertical morphing channels with natural convection, Numerical Heat Transfer Part A, 45, pp. 135-152, 2004.

[13] F. Marcondes, V. de Souza Melo, \& J. M. Gurgel, Numerical analysis of natural convection in parallel, convergent, and divergent open-ended channels, International Journal of Numerical Methods for Heat and Fluid Flow, 16 (3), pp. 304-323, 2006.

[14] A. Andreozzi, \& O. Manca, Thermal and fluid dynamic behaviour of symmetrically heated vertical channels with auxiliary plate, International Journal Heat Fluid Flow, 22, pp. 424-432, 2001.

[15] Fluent Incorporated, Fluent 6.1, User's Manual, 2003. 